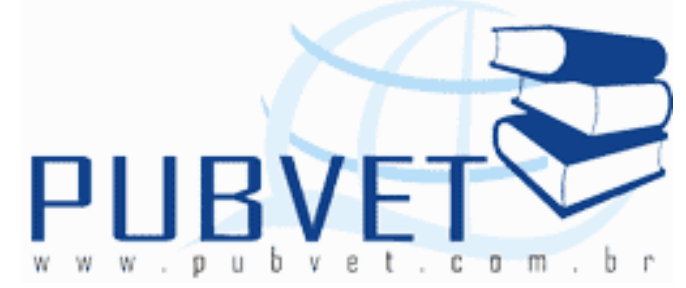

PUBVET, Publicações em Medicina Veterinária e Zootecnia.

\title{
Sistema de gestão ambiental: um diferencial estratégico competitivo na gestão de processos produtivos
}

\section{Lucas Ambrósio Bezerra de Oliveira ${ }^{1}$ e Israel José dos Santos Felipe ${ }^{2}$}

1 Professor de administração. Mestre em engenharia de produção, UFRN. lucasambro@gmail.com.

2 Professor de administração. Mestrando em administração, UFRN. israeljfelipe@gmail.com.

\section{Resumo}

O Sistema de Gestão Ambiental, ou SGA, se originou no desenvolvimento dos Sistemas de Qualidade; sua definição é proposta como parte de um sistema de gestão organizacional que a utiliza para implementação e regimentação de políticas ambientais e para o gerenciamento desses aspectos. Com a abertura comercial brasileira, a questão ambiental começou a fazer parte das rotinas de corporações, tanto de capital nacional quanto de capital estrangeiro, em função do aumento da concorrência internacional e da instalação, no cenário interno, de empresas multinacionais altamente competitivas. Considerando esse contexto, propõe-se discutir o uso do Sistema de Gestão Ambiental como ferramenta estratégica competitiva sustentável e como fonte de maximização do desempenho produtivo - eficiência em processos. Para a composição qualitativa deste trabalho, utilizaram-se fontes bibliográficas, documentais e estudos de caso que tratam da importância da Gestão Ambiental para o 
OLIVEIRA, L.A.B. e FELIPE, I.J.S. Sistema de gestão ambiental: um diferencial estratégico competitivo na gestão de processos produtivos. PUBVET, Londrina, V. 7, N. 3, Ed. 226, Art. 1495, 2013.

posicionamento estratégico institucional - frente às forças do mercado, como consumidores, produtores, fornecedores e organismos competentes de regulamentação e normalização. Em contrapartida, faz-se uma avaliação da sustentabilidade ambiental no ambiente competitivo empresarial, identificando-se questões relacionadas à implantação de um SGA com fins de competitividade; quando da realização de visitas técnicas, são identificadas informações que mostram um desenvolvimento ainda mais competitivo e acelerado, em detrimento de outras organizações; quando do estudo comparativo de indicadores que tratam da sustentabilidade entre empresas e atividades produtivas, cujos resultados, obtidos através de pesquisas realizadas em organizações locais, obtêm-se o norte das discussões que tratam de planejamento produtivo, sustentabilidade e uso de SGA para eficiência em processos.

Palavras-chave: Gestão Ambiental; Organismos de Regulamentação de Atividades Ambientais; Estratégia Competitiva.

\title{
Environmental management system: a differential competitive strategic management of productive processes
}

\begin{abstract}
The environmental management system, or SGA, originated in the development of quality systems; its definition is proposed as part of an organizational management system that uses it to implementation and regimentation of environmental policies and for the management of these aspects. With the Brazilian trade opening, the environmental issue began to be part of the routines of corporations, both of national capital and foreign capital, due to the increased international competition and internal scenario installation, multinational companies highly competitive. Given this context, it is proposed to discuss the use of the environmental management system as a strategic tool and as a source of sustainable competitive maximizing productive performance - efficiency in processes. For the qualitative composition of this
\end{abstract}


OLIVEIRA, L.A.B. e FELIPE, I.J.S. Sistema de gestão ambiental: um diferencial estratégico competitivo na gestão de processos produtivos. PUBVET, Londrina, V. 7, N. 3, Ed. 226, Art. 1495, 2013.

work used documentary and bibliographic sources, case studies that address the importance of Environmental Management to institutional strategic positioning - against market forces, as consumers, producers, vendors and regulatory bodies and standardisation. On the other hand, makes an assessment of environmental sustainability in business competitive environment, identifying issues related to deploying a SGA for competitiveness; When performing technical visits, are identified information showing an even more competitive and fast-paced development, to the detriment of other organizations; When comparative study dealing with indicators of sustainability between businesses and productive activities, whose results, obtained through surveys conducted in local organizations, obtained the North of discussions dealing with production planning, sustainability and use of SGA for efficiency in processes.

Keywords: Environmental Management; Regulatory bodies of environmental activities; Competitive Strategy.

\section{INTRODUÇÃO}

As organizações devem se adaptar a circunstâncias específicas, mas sempre de forma planejada. Tal planejamento é bastante facilitado por alguns instrumentos que por regulamentação (ou auto-regulamentação) devem ser considerados por todas as instituições que almejam um desenvolvimento sustentável. Esses instrumentos permitem aprimorar a percepção comum sobre o ambiente externo, de modo que se faz permissível adaptar toda a organização aos moldes da produção com sustentabilidade.

A regulamentação introduz nas empresas o imperativo de respeitar o ambiente, criando incentivos à condução de atividades inovadoras que culminam com a introdução de processos e tecnologias de produção mais limpas, reduzindo os impactos negativos de suas atividades. Trata-se, pois, de uma forma de sinalização para os agentes econômicos, dando visibilidade aos impactos nocivos, que provocam a sua consideração na racionalidade 
econômica e nos processos de análise e decisão associados.

O ambiente externo aponta para o aumento da consciência ecológica dos consumidores, que vêm encabeçando e apoiando movimentos organizacionais de instituições criadas para desempenhar determinadas funções junto à sociedade - no cunho da Responsabilidade Social. Para esse grupo de consumidores a legitimidade organizacional depende do cumprimento correto de suas atividades.

Porém, na realidade, as empresas operam num ambiente competitivo e dinâmico, sendo constantemente confrontadas com pressões externas que enfrentam de forma positiva para se manterem competitivas, optando, freqüentemente, por desenvolver ou adotar inovações (PARRY, 1997).

Dentro desse contexto, a preservação do meio ambiente vem ganhando um espaço crescente no cenário produtivo e no âmbito competitivo. $O$ desenvolvimento da consciência ecológica em diferentes camadas e setores da sociedade acaba por envolver também o setor empresarial, que vislumbra, no aumento dessa consciência, uma oportunidade de consolidar suas marcas, ampliar seu portfólio de produtos e serviços, aumentar a legitimidade institucional e angariar mais vantagens competitivas - por meio da Gestão Ambiental.

\section{2 - OBJETIVO}

Este trabalho busca evidenciar a importância da Gestão Ambiental como ferramenta de auxílio na estratégia competitiva. Estratégia competitiva, essa, que se vale da certificação como uso apropriado de suas ferramentas de gestão e planificação dos processos produtivos, assim como do auxílio estratégico nas políticas de marketing da empresa.

Então, conforme a fundamentação teórica proposta nesta pesquisa, a Gestão Ambiental Empresarial está contida no hall de ferramentas ideais para que a organização se torne competitivamente correta, convergindo com o novo perfil de consumidores, cada vez mais exigentes, quanto à qualidade ambiental e 
social de seus produtos, e com o posicionamento estratégico da empresa junto a órgãos competentes $e$ instituições governamentais de controle e normalização, parceiros e fornecedores - como também para com incentivos à causa da responsabilidade cívica, cidadã e ambiental.

\section{METODOLOGIA}

O presente estudo conta com dados obtidos a partir de pesquisas bibliográficas e documentais, pois o referencial teórico foi desenvolvido com base em material publicado em livros, meios eletrônicos, revistas, artigos e trabalhos científicos disponibilizados em editoriais, como os meios eletrônicos da Internet.

Baseado em Cervo e Bervian (1996), este artigo é exploratório, pois busca "a familiaridade com o fenômeno ou obter nova percepção e descobrir novas idéias do mesmo", incorporando ferramentas de gestão ambiental no contexto empresarial, como vantagem competitiva, frente às forças do mercado, dos consumidores e dos órgãos institucionais competentes de regulamentação e normalização.

À luz dessas teorias, dividiu-se este trabalho em duas etapas, em que na primeira foram realizadas observações à discussões que exploravam estudos de casos, relatados nas fontes pesquisadas, e, cronologicamente, fez-se altosquestionamentos acerca das estratégias mais eficazes para se obter as melhores vantagens competitivas.

Na segunda etapa desta pesquisa, para garantir sua consolidação no campo da ciência, aportou-se ao uso de "métodos científicos cruzados" - ou dados relativos à contraposição de teorias sugeridas ou consolidadas por academias, pesquisadores, autores e demais instituições interessadas no tema -, que, segundo Lakatos e Marconi (2006), pode ser visto como um procedimento lógico que vai orientar o pesquisador ao longo de sua pesquisa, para que o mesmo possa se manter dentro do que foi proposto.

O estudo está sendo aplicado junto a uma organização que, de fato, vem 
OLIVEIRA, L.A.B. e FELIPE, I.J.S. Sistema de gestão ambiental: um diferencial estratégico competitivo na gestão de processos produtivos. PUBVET, Londrina, V. 7, N. 3, Ed. 226, Art. 1495, 2013.

implementando um Sistema de Gestão Ambiental - a fim de constatar o objetivo descrito nesse trabalho.Utilizando-se do conceito de Indústria e de Organização, foi realizada uma pesquisa de campo, em forma de visita técnica, a fim de comprovar os dados obtidos com a pesquisa explanatória com as duas etapas, expostas nos parágrafos anteriores deste item.

Segundo Varian (2000), Indústria é o conjunto de empresas ou firmas dispostas a atuarem em toda uma cadeia produtiva, composta e disposta com o fim de contemplar diversos ramos de atividade em um só. Exemplos de Indústrias os quais se podem citar são as indústrias de alimentos, Indústrias de Produção de Computadores e Indústria Automobilística. Percebe-se, por inferência, que dentro de cada conjunto mencionado anteriormente de Indústria existem diversos tipos de empresa atuando e prestando apoio para que a atividade fim de cada uma dessas Indústrias se estabeleçam - a exemplo de empresas de transformação, logística, consultoria em Recursos Humanos, fornecedoras, etc.

Já Organização, para Maximiano (2000), é uma Empresa um Grupo Corporativo, uma firma, uma Instituição do Poder Público ou da Iniciativa Privada, uma Organização Não-Governamental ou mesmo um Grupo de Pessoas, com Missão, Visão e Valores que regem uma atividade fim, com objetivos e com uma filosofia proposta que visa a realização de uma tarefa fim e a concessão de uma variável a fim de atender interesses de determinados grupos de uma sociedade.

Utilizando-se como base os conceitos acima, foram selecionadas três organizações de uma Indústria Alimentícia localizada no perímetro industrial da Cidade do Natal / RN. Para tal, mensurou-se a quantidade precisa de empresas atuantes nessa indústria, segmentou-las por grupos de atividade, distintos entre si, tamanho e porte e, de modo aleatório, sob análises prévias, selecionou-se uma firma de cada grupo - buscando-se mensurar o grau de participação e de incorporação da Gestão Ambiental nas atividades de rotina e de produção das corporações selecionadas.

Nessas três organizações, já estabelecidas e prontificadas na metodologia de 
seleção e designação de empresas a serem visitadas, fez-se visitas técnicas às suas instalações, sob orientação de Gestores e Analistas das mesmas e apoio com fornecimento de informações organizacionais cruciais para a formação dos Resultados desta pesquisa (uma dessas empresas selecionadas, do ramo de Transformação - "Atividade de Transformação", como designado e conferido para a mesma nos Resultados, Item "6" - é objeto de continuidade deste estudo, ou seja, as pesquisas técnicas continuarão a ser realizadas em suas instalações com fins de retroalimentação deste estudo).

\section{GESTÃO AMBIENTAL: ALAVANCAGEM PARA A COMPETITIVIDADE EMPRESARIAL}

\subsection{Abordagem Histórica, Origem, Discussões e Avanços Sócio- Institucionais}

Na década de 1960, com a publicação do livro Primavera silenciosa em 1962 e com a fundação do Clube de Roma em 1968, os movimentos sociais pela preservação do meio ambiente ganharam força, causando grande impacto sobre a opinião pública. Esses movimentos vêem, deste então, divulgando a importância de um comportamento ambientalmente correto, influenciando a preferência dos consumidores - impulsionando, com isso, uma nova ordem no setor produtivo.

A temática ambiental passa, então, a ser fortemente debatida sob a análise de muitas áreas do conhecimento, como Biologia, Química, Geografia, Economia, Engenharia e Administração - por exemplo. Mas, segundo Moura (2000), foi em idos de 1990 que essa discussão ganhou força com a Gestão Ambiental.

Para Bruns (2007) a Gestão Ambiental visa ordenar as atividades humanas para que estas originem o menor impacto possível no meio. Ela possui um caráter multidisciplinar, em que profissionais de diversos campos podem atuar na área, desde que devidamente habilitados. Pelo seu conceito, a Gestão 
OLIVEIRA, L.A.B. e FELIPE, I.J.S. Sistema de gestão ambiental: um diferencial estratégico competitivo na gestão de processos produtivos. PUBVET, Londrina, V. 7, N. 3, Ed. 226, Art. 1495, 2013.

Ambiental é bastante abrangente e contempla a racionalidade dos usos de todos os recursos naturais renováveis ou não.

Segundo a NBR ISO 14.001 (2004), a Gestão Ambiental:

[...] É parte de um sistema global de administração que provê ordenamento e consistência para que as organizações abordem suas preocupações ambientais, através da alocação de recursos, definição de responsabilidades e avaliação contínua de práticas, procedimentos e processos, voltados para planejamento, implementação, verificação e analise critica pela alta administração para manter a política ambiental estabelecida pela empresa.

Antonius (1999) revela que, de modo geral, o gerenciamento ambiental pode ser conceituado como a integração de sistemas e programas organizacionais que permitam:

- O controle e a redução dos impactos no meio ambiente, devido às operações ou produtos;

- O cumprimento de leis e normas ambientais;

- O desenvolvimento e uso de tecnologias apropriadas para minimizar ou eliminar resíduos industriais;

- O monitoramento e avaliação dos processos e parâmetros ambientais;

- A eliminação ou redução dos riscos ao meio ambiente e aos seres vivos, inclusive seres humanos;

- A utilização de tecnologias limpas (clean technologies), visando minimizar os gastos de energia e materiais;

- A melhoria do relacionamento entre a comunidade e o governo;

- A antecipação de questões ambientais que possam causar problemas ao meio ambiente e, particularmente, à saúde humana.

De acordo com Bianchi (2003), a certificação de um Sistema de Gestão Ambiental tem por objetivo certificar que uma empresa adota um Sistema de 
Gestão Ambiental em conformidade com determinada norma, como por exemplo, a ISO 14.001. Mais recentemente, esses instrumentos passaram a integrar o marketing da empresa que possui o certificado, representando um diferencial a mais no mercado.

\subsection{Discussão acerca do Sistema de Gestão Ambiental}

Em um contexto onde o mercado consumidor exige cada vez mais que os produtos e serviços sejam concebidos de forma sustentáveis, que sejam ecologicamente corretos e que reduzam a agressão ao meio ambiente e a saúde humana, de acordo com Ottman (1994), o Sistema de Gestão Ambiental passa a ser não apenas uma atividade filantrópica ou assunto de ambientalistas. O SGA passa a ser uma ferramenta que propicia a maximização do desempenho e os ganhos financeiros; sua implantação chega a ser questão de sobrevivência.

Ottman (1994), afirma que as organizações que não responderem a questões ambientais arriscam-se em perder a sintonia com o consumidor; já os atributos chamados "compatibilidade ambiental" - a qualidade verde de um produto - seriam determinantes na decisão de compra.

O Sistema de Gestão Ambiental teve sua origem com o desenvolvimento dos sistemas de qualidade. É uma ferramenta de gestão que possibilita a uma organização de qualquer dimensão ou tipo controlar o impacto das suas atividades no ambiente.

Sistema de Gestão Ambiental, ou SGA, é definido como a "parte de um sistema da gestão de uma organização que se utiliza da própria SGA para desenvolver e implementar sua política ambiental e para gerenciar seus aspectos ambientais" (NBR ISO 14.001, 2004). Ele fornece um detalhe adicional no programa ambiental. Estabelece procedimentos, instruções de trabalho e controles, possibilitando uma abordagem estruturada para definição dos objetivos, para atingi-los e demonstrar que foram atingidos. É importante ressaltar que nem todas as empresas com SGA são certificadas com a série 
ISO 14.000.

Os SGA não são obrigatórios, ou seja, não há legislação de qualquer nível, em qualquer lugar do mundo, que obrigue uma organização produtiva a realizar o desenvolvimento e sua implantação. Mas, como já citado, o mercado, cada vez mais, vem estabelecendo, como condição de comercialização de produtos e serviços, a certificação formal dos fornecedores em termos de gestão ambiental. Isto implica em mudança de cultura e até mesmo mudança estrutural. A questão passa a ser sistêmica (MARTINELLI, 2006), tornando-se parte integrante da atividade de toda a organização, de cada funcionário, desde a alta administração até o chão de fábrica. Segundo Vilas (2006), algumas empresas adotam os requisitos ambientais meramente pela imposição das leis existentes, como os padrões de lançamento de efluentes na rede de saneamento ou nos rios; outras por representarem fatores competitivos que podem antecipar um padrão de consumo sustentável, apontando uma tendência de se impor requisitos ambientais. Essa noção envolve toda a cadeia de suprimento.

No Brasil, o Sistema de Gestão Ambiental surgiu um pouco antes da série de normas ISO 14.000 serem publicadas oficialmente. A Bahia Sul Celulose S.A. foi a primeira empresa a conquistar a certificação ISO 14.000 , em setembro de 1996, tendo o BVQI - Bureau Veritas Quality International - como certificador. A empresa já havia sido certificada em conformidade com a British Standards BS7750.

\subsection{A ISO 14.000}

A International Organization for Standardization - ISO - foi fundada em 23 de fevereiro de 1947, com sede em Genebra na Suíça. Trata-se de uma organização não governamental composta por Organismos Nacionais de Normatização, contando com um representante por país filiado. Atualmente a ISO conta com 157 países (ISO, 2006) e o principal objetivo é criar normas internacionais de padronização em todos os campos técnicos, exceto na 
OLIVEIRA, L.A.B. e FELIPE, I.J.S. Sistema de gestão ambiental: um diferencial estratégico competitivo na gestão de processos produtivos. PUBVET, Londrina, V. 7, N. 3, Ed. 226, Art. 1495, 2013.

eletricidade e eletro-técnica, que representam e traduzem o consenso dos diferentes países. O Brasil está representado na ISO através da ABNT, Associação Brasileira de Normas Técnicas. As normas da ISO publicadas pela ABNT recebem o nome de NBR ISO "número da série".

A série ISO 14.000 foi criada pelo Comitê Técnico 207 (TC 207), envolvendo um conjunto amplo de cinco Normas, que envolvem não somente a Gestão Ambiental, mas também outros aspectos relacionados ao meio ambiente e aos produtos manufaturados. Gavronski (2003) diz que apenas a NBR ISO 14.001 (Sistemas de Gestão Ambiental - Especificação e diretrizes para uso), é passível de certificação. É importante citar que nem todas as normas da série foram publicadas pela ABNT no Brasil.

Segundo definição do site Ambiente Brasil (2007),

A ISO 14.000 é um conjunto ou série de normas da ISO, de caráter voluntário, que visa a sistematizar os princípios de gestão ambiental nas empresas. Baseada numa precursora inglesa, a British Standard - BS7750 - teve, em relação a esta, sua abrangência expandida e sua especificidade minimizada, de forma a ser aceita em todo o mundo.

A ISO 14.000 tem como objetivo fornecer assistência para as organizações na implantação ou no aprimoramento de um Sistema de Gestão Ambiental (SGA). A Norma oferece diretrizes para o desenvolvimento e implementação de princípios e Sistemas de Gestão Ambiental, bem como sua coordenação com outros sistemas gerenciais. Tais diretrizes são compatíveis com quaisquer "organizações" (NBR ISO 14.000:2004, p. 3). A ISO 14.000 é consistente com a meta de "Desenvolvimento Sustentável" (WCED, 1987).

As diretrizes são destinadas ao uso interno como uma ferramenta gerencial voluntária, não sendo apropriada para uso por parte de entidades de Certificação / Registro de SGA, como uma Norma de especificações. Elas se baseiam nos elementos centrais da especificação para SGA encontrados na ISO 
OLIVEIRA, L.A.B. e FELIPE, I.J.S. Sistema de gestão ambiental: um diferencial estratégico competitivo na gestão de processos produtivos. PUBVET, Londrina, V. 7, N. 3, Ed. 226, Art. 1495, 2013.

14.001 e incluem importantes elementos adicionais para um Sistema de Gestão Ambiental amplo.

\section{A GESTÃo AMBIENTAL E A COMPETITIVIDADE}

\subsection{A Relação do SGA com o Desenvolvimento Organizacional}

Com a abertura comercial brasileira na década de 1990, a questão ambiental começou a fazer parte da gestão das empresas brasileiras, em função do aumento da concorrência internacional. Além da ampla competitividade externa e interna e da emergência do capitalismo natural, as expectativas dos clientes não se cingem na procura de um determinado nível de qualidade ao menor custo. Eles estão cada vez mais informados e predispostos a comprar e usar produtos que respeitem o ambiente.

Segundo Porter \& Linde (apud Estrela \& Leite, 2007), dados de uma pesquisa mostram que o debate entre competitividade e o meio ambiente tem sido abordado de modo equívoco sempre que se colocam os custos ambientais como um entrave à competitividade, ou seja, sempre que não se considera o papel das inovações para reverter esses custos em benefícios.

Porter \& Linde (apud Estrela \& Leite, 2007) argumentam, ainda, que as novas tecnologias ou inovações relacionam-se a questão ambiental minimizando o custo dos danos ambientais, quando eles ocorrem, ou indo "direto as raízes da poluição, aumentando a produtividade dos recursos em primeiro lugar". Assim as inovações para ajuste à regulamentação ambiental podem resultar em economia de tempo e dinheiro.

Logo, a adoção de um Sistema de Gestão Ambiental, com a definição de funções, responsabilidades e autoridades, confere vantagens competitivas à organização por meio das práticas ambientais, que vão contribuir com a redução de custos, tanto operacionais quanto de passivo ambiental e, conseqüentemente, diferenciando seus produtos. Além disso, de acordo com Estrela \& Leite (2007), um SGA também contribui para a maximização da 
OLIVEIRA, L.A.B. e FELIPE, I.J.S. Sistema de gestão ambiental: um diferencial estratégico competitivo na gestão de processos produtivos. PUBVET, Londrina, V. 7, N. 3, Ed. 226, Art. 1495, 2013.

eficiência dos processos, redução de insumos utilizados nos processos produtivos, minimização de tratamento de resíduos e efluentes e re-trabalho.

Para Fontenele (2007),

A diferenciação "verde" pode ser uma estratégia efetiva quando o produto tem genuína vantagem ambiental e a empresa é capaz de comunicar tal vantagem para o público. A gestão ambiental, bem como a legislação, deixou de ser somente uma questão legal para ser uma questão de estratégia competitiva, de crescimento e uma saída para um mercado saturado.

Desse modo, são gerados benefícios para o meio ambiente e vantagens para a organização. Além disso, a adoção desses procedimentos, bem como, a definição de regras escritas para a realização de operações com alto potencial de impacto ambiental, reduziram os riscos ambientais (emissões, derrames, acidentes) daquelas atividades. Conforme estudo de Faria (2000), várias empresas obtiveram retorno de investimento e redução de custos a partir da implantação do SGA.

\subsection{A geração de vantagens competitivas}

A Gestão Ambiental, mais do que uma atitude politicamente correta, tornouse uma indispensável vantagem e estratégia competitiva. De acordo com Porter (1991), "a estratégia competitiva visa estabelecer uma posição lucrativa e sustentável contra as forças que determinam a concorrência da indústria" e "a vantagem competitiva surge fundamentalmente do valor que uma empresa consegue criar para com a visão e percepção de seus consumidores e clientes - e que ultrapassa o custo de fabricação despendido pela empresa para tal".

Para Porter (1991), existem dois tipos básicos de vantagem competitiva: liderança de custo e diferenciação. Essas vantagens somadas à área de atuação da empresa resultam em três estratégias genéricas: liderança de custo, diferenciação e enfoque, que podem ser usadas individualmente ou em 
OLIVEIRA, L.A.B. e FELIPE, I.J.S. Sistema de gestão ambiental: um diferencial estratégico competitivo na gestão de processos produtivos. PUBVET, Londrina, V. 7, N. 3, Ed. 226, Art. 1495, 2013.

conjunto a fim de se obter uma posição sustentável no longo prazo.

A estratégia de diferenciação, que se baseia em oferecer produtos, com características específicas, que permitam que se cubra um preço-prêmio por esse devido produto, pode estar sendo incorporada dentro da organização como fator competitivo, por meio da Gestão Ambiental.

A opção pela estratégia competitiva de diferenciação faz com que a empresa invista mais pesado em Imagem, Tecnologia, Assistência Técnica, Distribuição, Pesquisa e Desenvolvimento, Recursos Humanos, Pesquisa de Mercado e Qualidade, com a finalidade de criar diferenciais para o consumidor.

Orsato (2003) propõe um modelo que identifica os elementos - tipos genéricos - envolvidos na Gestão Ambiental Corporativa. Para o autor, é fundamental esta separação para identificar condições específicas nas quais as Estratégias Ambientais Corporativas podem melhorar a competitividade da empresa, visto que até 0 momento não foram tratados como áreas independentes da ação estratégica.

De acordo com a estrutura da empresa e qual o setor em que ela esteja inserida, o posicionamento da mesma no mercado e o foco competitivo mais apropriado ou cabível à sua realidade, poderá ela adotar uma das estratégias ambientais, conforme na matriz proposta pelo autor. Essa matriz combina os elementos com os tipos básicos de vantagem competitiva com as quais uma empresa busca alcançar, gerando quatro estratégias gerais, representadas na Figura 1.

Lembra Orsato (2003), ainda, que além dessas estratégias, as empresas podem, até mesmo, desenvolver estratégias mais ambiciosas e explorar soluções mais arriscadas e radicais. Neste aspecto confere-se aquilo que se pode chamar de Inovações Ambientais ou Sistemas Inovadores de Gestão Ambiental, SIGA, que seria a mudança de métodos e formas de produção com uso de tecnologia limpa, produtos "Ambientalmente Corretos" ou adaptações às exigências e normalizações propostas pela ISSO 14.000 e demais instituições regulamentadoras (incluindo as nacionais, estatais e da sociedade civil). 
OLIVEIRA, L.A.B. e FELIPE, I.J.S. Sistema de gestão ambiental: um diferencial estratégico competitivo na gestão de processos produtivos. PUBVET, Londrina, V. 7, N. 3, Ed. 226, Art. 1495, 2013.

A primeira estratégia, segundo Orsato (2003), é a produtividade de recursos. Nela, os fatores sociais, econômicos e produtivos influenciam empresas a atingirem um grau significativo de produtividade de trabalho e capital, possibilitando-as a reduzir substancialmente os custos de manufatura e o preço final dos seus produtos. Estudos demonstram que o potencial de um novo conjunto de práticas empresarias, para desenvolver a produtividade de recursos, pode até emergir em um novo sistema econômico.

Quanto à segunda estratégia, chamada de "Além da Conformidade Legal", a mesma diz que a imagem corporativa pode ser melhorada, influenciando uma opinião pública positiva sobre as práticas de Gestão Ambiental. Um exemplo disso é a Toyota, que passou a exigir dos seus fornecedores Sistemas de Gestão Ambiental em conformidade com a ISO 14.001 - em virtude dos presentes avanços nas relações organizacionais e na exigência consciente por parte dos agentes da sociedade civil, inclusive clientes e consumidores, o que vem gerando impactos relevantes no modelo econômico atual; ou seja, a imagem empresarial pode sofrer influência negativa em virtude de a opinião pública tomar conhecimento de possíveis distorções ou inconformidades em sua cadeia e filosofia produtiva (dentre eles, e principalmente, fornecedores e parceiros).

Em outras palavras, não adianta se adotar estratégias de "Marketing Verde" e voltar seus métodos produtivos à filosofia Ambiental se parceiros, fornecedores e aliados não concebem o mesmo ou da mesma forma.

Produtos e serviços ecologicamente orientados são requisitos da terceira estratégia. Os produtos ecologicamente corretos representam, hoje, um nicho de mercado definido, explorado por todas as empresas do mundo. Porém, Orsato (2003) diz que, para isso, é necessário observar se os consumidores estão dispostos a pagar pelos custos da diferenciação ecológica; se as informações confiáveis sobre o desempenho ambiental do produto precisam estar disponíveis para o consumidor; se a diferenciação deve ser difícil de ser imitada pelos concorrentes.

A última estratégia é a liderança de custo ambiental. No conceito tradicional 
de liderança de custo, a vantagem competitiva é obtida quando a empresa apresenta os custos mais baixos do setor. Porém, para se obter vantagem de custo se faz necessário considerável esforço. Além da difícil redução de custo, a redução dos impactos ambientais associados aos processos, acessibilidade à matéria-prima "verde", tecnologias limpas e exigência de pré-requisitos na elaboração de estratégia baseada em liderança de custo ambiental tornam essa estratégia a mais ambiciosa de todas.

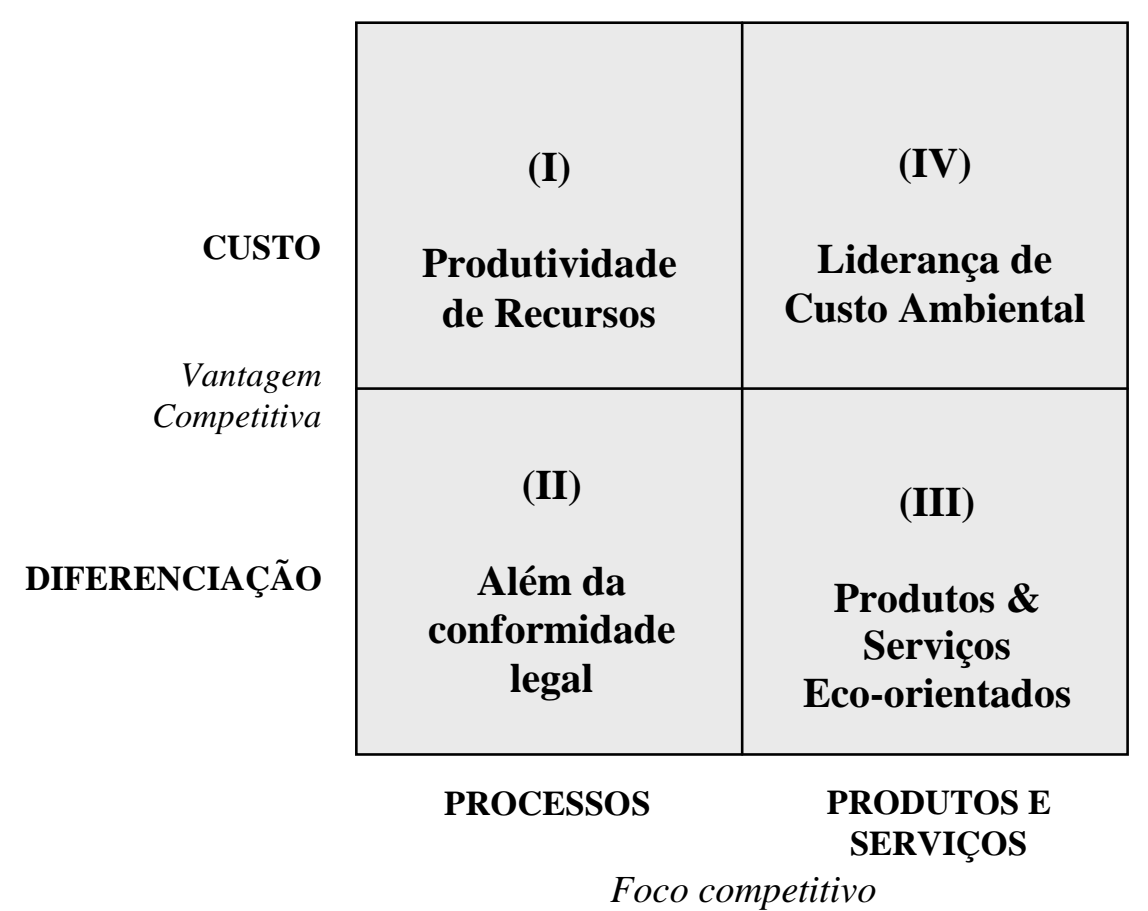

\section{FIGURA 1 - Tipos genéricos de estratégia ambiental corporativa}

Fonte: Adaptado por Orsato, 2003.

Vale ressaltar que a distinção entre os processos organizacionais e os produtos e serviços ofertados por uma determinada empresa não são apenas teorizados ou não possuem implicações e influências diretas na forma como a essa organização irá atuar no segmento ambiental. A própria natureza da atividade organizacional implica interdependência entre os processos. Assim, além de se fazer possível ou acessível para essa empresa se focalizar em um único tipo de estratégia genérica, a fim de melhor gerir seus recursos 
organizacionais, a organização em questão poderá ultrapassar as fronteiras entre as quatro possíveis estratégias, visto que elas não são rígidas.

\section{ESTUDO MACROORGANIZACIONAL NO PERÌMETRO DA INDÚSTRIA NATALENSE}

Com fins de mensurar e avaliar os conceitos expostos pelos autores e cientistas abordados neste trabalho, fez-se um estudo técnico, através de visitas presenciais e recolhimento de dados produtivos em organizações situadas no perímetro industrial da Cidade do Natal, estado do Rio Grande do Norte, sendo pesquisada uma indústria do ramo alimentício, composta por empresas do ramo produtivo de escala de grande porte em alimentos, empresas de médio e pequeno porte do ramo de serviços de apoio técnico na área de gestão burocrática e contábil e distribuidoras de grande porte.

Sendo selecionadas três organizações dessa indústria de forma aleatória fazendo-se uma mensuração da quantidade de empresas atuantes na indústria, dividindo-as por grupo de atividade, tamanho e porte, denominando esse grupos como "Atividade de Transformação", "Atividade de Apoio Técnico" e "Atividade Logística" e, sob análises prévias, selecionando uma firma de cada grupo - buscou-se:

- mensurar o grau de participação e de incorporação de Sistemas de Gestão Ambiental em suas atividades de rotina produtiva;

- mensurar o potencial interesse dessas empresas em incorporar Sistemas de Gestão Ambiental em sua efetiva atividade produtiva e os impactos obtidos a partir de feedbacks concebidos por agentes externos às organizações pesquisadas;

- mensurar e analisar, nas empresas que já têm incorporado Sistemas de Gestão Ambiental em sua atividade produtiva, os impactos financeiros, produtivos, de eficiência e acerca dos resultados conferidos em âmbito 
OLIVEIRA, L.A.B. e FELIPE, I.J.S. Sistema de gestão ambiental: um diferencial estratégico competitivo na gestão de processos produtivos. PUBVET, Londrina, V. 7, N. 3, Ed. 226, Art. 1495, 2013.

mercadológico - no que tange clientes e consumidores potenciais (Estratégias de Participação Global em Mercado).

Na empresa enquadrada no ramo de "Atividade de Transformação", apesar de não implementado por completo o SGA nos seus procedimentos produtivos, em virtude da necessidade de se fazer adaptações na estrutura e no domínio técnico dos colaboradores, a utilização de embalagens recicladas e retornáveis preeminentemente pôde, no segundo caso, reduzir custos de forma significativa. Segundo o Gerente Administrativo da empresa em questão, "apesar de um pouco mais baratos, a parceria fechada com repassadores e vendedores finais contribui para a não necessidade de se produzir levas e levas de embalagens de plásticos. Periodicamente, veículos da transportadora se encarregam de ir buscar os frascos de vidro nas lojas repassadoras e comercializadoras dos nossos produtos; algumas contam com equipes e até minigrupos parceiros de suas lojas para a separação e recolhimento desses frascos". Ou seja, neste primeiro caso pesquisado, além da redução de custos operacionais e ambientais, têm uma espécie de formação e alimentação de toda uma cadeia produtiva, com ampliação de seus limites.

Os ganhos não o são somente ambientais e financeiros, mas sociais, com a geração de oportunidades empregatícias, de implementação de novas idéias e do surgimento de novas empresas. Quanto às embalagens recicladas, segundo o Gerente Administrativo da mesma empresa - colaborador o qual se dispôs a contribuir com o exame dos dados de sua instituição para esta pesquisa -, em que se realizou a visita técnica e que se enquadra no ramo de "Atividade de Transformação", o custo financeiro gerado com o uso de embalagens recicladas emagrecem, a principio, o caixa da empresa.

Contudo, aumentando-se a escala produtiva, em função do aumento das vendas sob a ótica mercadológica de instituição social e ambientalmente responsável, a qual essa organização vem trabalhando sobre sua imagem e marca, através de campanhas de Marketing e de campanhas e estratégias traçadas junto a aliados e fornecedores, em cerca de 24 meses essa mesma empresa usufruirá dos retornos financeiros positivos, tanto no que tange a 
OLIVEIRA, L.A.B. e FELIPE, I.J.S. Sistema de gestão ambiental: um diferencial estratégico competitivo na gestão de processos produtivos. PUBVET, Londrina, V. 7, N. 3, Ed. 226, Art. 1495, 2013.

elevação da Receita em função da soma dos Custos Totais como no que diz respeito à fidelização de parcerias e de clientes potenciais - além da expansão da demanda para uma fatia de consumidores ainda desatenta a esse fato, incluindo stakeholders exigentes para com questões sociais e ambientais.

Esses resultados já podem ser discutidos levando em conta as variáveis extremas e periféricas do mercado em virtude de já haverem empresas do cenário local se beneficiando desse tipo de estratégia, como é o caso de empresas de produção de calçados, vestuário e até alimentícias - também.

No que se refere aos resultados obtidos com as pesquisas realizadas em empresa que presta serviço a devida firma discutida nos parágrafos anteriores, pelo fato de a mesma atuar no ramo da Gestão Burocrática, sua principal fonte de degradação é o uso exacerbado de papel. Um dos Gestores desta empresa afirmou que ainda não existia uma preocupação concreta ou uma ação vigente em prol do melhor uso de papelório. O uso racionalizado dessa matéria-prima visa à redução de gastos administrativos, mas nada com intenções ambientais reais. Contudo, o Gestor entrevistado, e que se dispôs a realizar a entrevista para este trabalho, externou o interesse de planejar e aplicar programas de conscientização ambiental junto aos colaboradores, visando dar maior sentido à sua política de redução de gastos com as atividades de sua empresa.

Segundo o Gestor em questão, "pilhas, papéis, tinta de impressora e canetas são exemplos de recursos produtivos da nossa empresa que podem ser racionalizados, a fim de reduzir custos com a nossa atividade e, sob a nossa ótica gestora, que podem ser melhor geridos tanto no nosso espaço (empresa) quanto na residência de cada um de nós daqui". Continuando com as palavras do Gestor, "sei da importância da consciência ambiental em todos os aspectos da nossa sociedade, não penso somente no capital da empresa, e sei também que se eles, nossos colaboradores, se acostumarem com essa filosofia de trabalho e incorporarem-na em seu estilo de vida, acabarão por levá-la até suas residências $e$, inclusive, até as outras empresas que os mesmos venham colaborar algum dia do futuro". Foi percebido também nos murais e nas bancadas de recepção da empresa em questão pequenos folhetos 
OLIVEIRA, L.A.B. e FELIPE, I.J.S. Sistema de gestão ambiental: um diferencial estratégico competitivo na gestão de processos produtivos. PUBVET, Londrina, V. 7, N. 3, Ed. 226, Art. 1495, 2013.

da empresa anteriormente mencionada, que se enquadra no grupo de "Atividade de Transformação", informando sua nova política de operação e trabalho com embalagens recicladas, em forma de campanha.

No que se refere à organização que se configura no grupo de "Atividade Logística", seu principal produto, o transporte, pode ser considerado, a princípio, o mais degradante dentre os três grupos aplicados nesta pesquisa. Por operar com veículos de grande porte, como caminhões e caminhonetes, a principal fonte combustível dessas máquinas é o Diesel. Foi percebido, todavia, a possibilidade de se reduzir o porte desses veículos, em função do tamanho das demandas por transporte, solicitadas pela Indústria a qual ela se situa. Com a redução do porte desses veículos, para meios de transporte menores, como veículos pick ups e modelos mini-caminhonetes, a substituição de uso de combustíveis como Diesel ou Gasolina para Álcool ou mesmo Gás Natural Veicular, se faz possível não apenas a redução dos custos ambientais, visto a redução na emissão de agente poluentes à atmosfera, mas a redução nos seus gastos operacionais - em virtude do preço final do Gás Natural Veicular ser o mais baixo do mercado, dentre todos os combustíveis dispostos à venda na cidade. Além disso, consomem menos combustível e realizam o transporte mais rapidamente, o que permite a essa empresa aumentar sua demanda em função do aumento da eficiência e agilidade na realização de suas tarefas.

O Analista de Logística desta organização, membro o qual se fez possível a entrevista para esta pesquisa, externou suas intenções em utilizar, em futuro não superior a 36 meses, Biodiesel como principal produto combustível aos seus veículos. Externou ainda os planos de sua organização em vender seus veículos de maior porte com fins de adquirir veículos de menor porte, porém, em quantidades unitárias maiores. Dessa forma, segundo o mesmo Analista de Logística, fazendo-se essa modificação a redução com gastos com combustíveis e manutenção técnica reduziriam significativamente e seu aumento, por ventura, somente se daria em função do aumento da demanda por seus serviços. Logo, o aumento dos custos se daria sob a ótica da função 
OLIVEIRA, L.A.B. e FELIPE, I.J.S. Sistema de gestão ambiental: um diferencial estratégico competitivo na gestão de processos produtivos. PUBVET, Londrina, V. 7, N. 3, Ed. 226, Art. 1495, 2013.

do aumento no faturamento; aumentando-se a demanda por veículo aumentam-se os dividendos e o retorno da atividade.

Foi conferido também o uso de papel reciclado em documentos encontrados sobre birôs e mesas de recepção. O Analista de Logística contemplou que o uso desse tipo de papel, de fato, se deve à consciência ambiental presente na opinião de alguns colaboradores, que fizeram essa sugestão; sem empecilhos ou questionamentos, a sociedade corporativa da organização em questão absorveu a referida sugestão e a aplicou em toda a empresa.

É interessante frisar que o uso de planejamento e de visão estratégica agrega, realmente, um diferencial competitivo significativo. No que tange o uso de ferramentas de Gestão Ambiental, sem necessariamente essas ferramentas serem associadas a órgãos competentes de normatização e regulamentação, é possível reduzir gastos operacionais, produtivos, dispêndios financeiros e, sobretudo, ambientais - sob toda uma ótica de planejamento e ação de longo prazo, que vem somente para agregar e gerar mais valor à instituição presente. A sociedade civil, incluindo stackholders de diversas camadas organizacionais, como consumidores, fornecedores e parceiros, perceberá a presença de tangência ambiental nas empresas que estão ao seu alcance; e não só cobrarão das mesmas as devidas adaptações e reinserções produtivas, mas optarão pelas "Ambientalmente Mais Lucrativas".

\section{CONSIDERAÇÕES FINAIS}

A evolução das organizações ao longo do tempo tem gerado uma série de impactos ambientais. Diante disso, a sociedade intensificou as cobranças sobre essas organizações, exigindo um maior cuidado com o meio ambiente. A legislação vem se tornando mais rígida, imputando sanções aos infratores e obrigando às Indústrias encararem com seriedade e responsabilidade a variável ambiental.

Como uma conseqüência natural da evolução da mentalidade humana, em relação à utilização dos recursos naturais de um modo mais sábio, a Gestão 
OLIVEIRA, L.A.B. e FELIPE, I.J.S. Sistema de gestão ambiental: um diferencial estratégico competitivo na gestão de processos produtivos. PUBVET, Londrina, V. 7, N. 3, Ed. 226, Art. 1495, 2013.

Ambiental se firma como uma ferramenta de excelência, propiciando benefícios à organização que a põe em prática, bem como, ao meio ambiente.

Além disso, a Gestão ambiental tomou um caráter estratégico e competitivo dentro das organizações, revelando oportunidades ocultas, como a redução de custos, melhora da imagem institucional, aumento da produtividade, aumento do portfólio de produtos e geração de um maior comprometimento por parte dos colaboradores para com o meio ambiente.

De acordo com Porter \& Linde (1995), não existe incompatibilidade entre o desenvolvimento empresarial ou competitividade e preservação ambiental, sendo conciliáveis e, até, complementares. Dessa maneira, a proteção ambiental tem uma nova dimensão econômica, que se traduz em incentivos à reestruturação e inovação no seio das organizações, induzindo melhorias de produtividade e eficiência no uso dos recursos - podendo, na conclusão de toda a análise gerencial em sua prática, proporcionar reduções nos custos (em virtude da concessão de diferenciais competitivos), que acabarão por tornar as empresas que fazem uso de SGA mais competitivas e não menos, como afirma uma parcela de empresários, até o presente momento.

Refletindo na afirmação acima e na afirmação de Porter $\&$ Linde, percebe-se que a relação entre atividades econômica e preservação da qualidade do ambiente não é necessariamente contraditória, mas sinérgica. Seja pela melhoria da imagem junto aos consumidores, seja pelos ganhos de produtividade decorrentes da utilização mais eficiente dos recursos, através de revisão dos produtos ou otimização dos processos produtivos e organizacionais, atividade econômica e preservação ambiental podem sim serem aliadas e andarem de mãos atadas.

Por fim, a adoção de estratégias competitivas no contexto ambiental dota as organizações de diferenciais e vantagens competitivas, gerando uma zona de excelência ambiental, onde a produtividade de recursos e as práticas organizacionais são melhoradas (significativamente). A implantação dessas estratégias não é tarefa fácil, mas o resultado do esforço são compensadores, tanto para a organização que a pratica, como um todo, como para o meio 
OLIVEIRA, L.A.B. e FELIPE, I.J.S. Sistema de gestão ambiental: um diferencial estratégico competitivo na gestão de processos produtivos. PUBVET, Londrina, V. 7, N. 3, Ed. 226, Art. 1495, 2013.

ambiente e para os seres vivos (incluindo os seres humanos), conforme visto neste estudo.

\section{REFERÊNCIAS}

[ABNT] Associação Brasileira de Normas Técnicas. NBR ISO 14.001:2004. Sistemas de gestão ambiental - Requisitos com orientação para uso: ABNT, 2004.

ANTONIUS, P. A. J. A exploração dos recursos naturais face à sustentabilidade e gestão ambiental: uma reflexão teórico-conceitual. Belém - PA: NAEA, 1999.

AMBIENTE BRASIL. Glossário. Disponível em: <

http://www.ambientebrasil.com.br/composer.php3?base=./educacao/index.php3\&conteudo=./ glossario/i.html>. Acesso em: 05 de jun. 2008.

BIANCHI, P. N. L. Meio ambiente: certificações ambientais e comercio internacional. 1a edição. Curitiba: Juruá, 2003.

BRUNS, G. B. Afinal, o que é Gestão Ambiental? Disponível em: < http://www.ambientebrasil.com.br/composer.php3?base=./gestao/index.html\&conteudo=./ges tao/artigos/artigo_gestao.html>. Acesso em: 05 de jun. 2008.

CERVO, A. L.; BERVIAN, P. A. Metodologia científica. 4. ed. São Paulo: Makron Books, 1996. ESTRELA, G. Q.; LEITE, M. S. A. Gestão ambiental sob à ótica dos custos. Disponível em: <http://www.cueroamerica.com/tecnologia_calzado/tecnologia_calzado_06.htm>. Acesso em: 05 de jul. 2008.

FARIA, H. M. Uma discussão a respeito dos benefícios econômicos da gestão ambiental. 2000. Dissertação (Mestrado em Engenharia da Produção) - Escola Federal de Engenharia de Itajubá - MG. Disponível em: < http://read.adm.ufrgs.br/read30/artigos>. Acesso em: 08 de jun. 2007.

FONTENELE, R. E. S.; DIAS , J. G.; JÚNIOR, K. C. S. Práticas ambientais sustentáveis como fator competitivo das empresas industriais no comércio internacional.

Disponível em: <

http://www.fgvsp.br/iberoamerican/Papers/0097_Artigo\%20MNI\%20Meio\%20Ambiente.pdf>. Acesso em: 08 de jun. 2008.

MARTINELLI, D. P. Visão Sistêmica e Administração. São Paulo: Saraiva, 2006.

MAXIMIANO, A. C. A. Introdução à administração. 5 ed. São Paulo: Atlas, 2000.

MOURA, L. A. A. Qualidade e gestão ambiental: sugestões para implantação das normas ISO 14000 nas empresas. 2. ed. São Paulo: Juarez de Oliveira, 2000.

ISO. Overview of the ISO system. Disponível em:

<http://www.iso.org/iso/en/aboutiso/introduction/index.html\#three>. Acesso em: 05 de jun. 2008.

OTTMAN, J. A. Marketing verde. São Paulo: Ed Makron Books, 1994.

PARRY, W. H. Pollution Regulation and the Eficiency Gains from Technological

Innovation: Discussion Paper 98-04. Washington: Resources for the Future, 1997.

PORTER, M. E. Estratégia Competitiva. Rio Janeiro: Campus, 1991.

PORTER, M. E.; CLAAS, V. L. Toward a New Conception of the EnviromentCompetitiveness 
VILAS, L. H. L. Responsabilidade Corporativa. Disponível em:

<http://www.cebds.org.br/cebds/artigos.asp?TD=1>. Acesso em: 05 de jun. 2008.

ORSATO, R J. Posicionamento ambiental estratégico. Disponível em:

<http://read.adm.ufrgs.br/read30/artigos. >. Acesso em: 08 de jun. 2008.

VARIAN, H. R. Microeconomia: princípios básicos. Tradução da $4^{a}$ Edição Americana. Rio de Janeiro: Editora Campus, 2000.

WCED. World Comission on Environment and Development. Our Commom Future. Oxford and New York: Oxford University Press, 1987. 